\title{
Características del conflicto en las organizaciones de salud y estrategias para su resolución
}

\author{
Characteristics of the conflict in the healthcare organizations and strategies \\ for its solution
}

\author{
Patrizio Petrone, MD, PhD, MPH, MHSA, MAAC, FACS ID
}

\begin{abstract}
Coeditor, Revista Colombiana de Cirugía. Associate Professor of Surgery, NYU Long Island School of Medicine. Director of Surgical Research. Program Director of the International Research Fellowship. Department of Surgery, NYU Langone Hospital_Long Island, Mineola, New York, USA
\end{abstract}

Estaba enojado con mi amigo: le manifesté mi ira, la ira terminó. Estaba enojado con mi enemigo: me quedé callado, y mi ira aumentó.

William Blake (1757-1827)

\section{Introducción}

El conflicto se define como la confrontación entre dos o más actores y es la resultante de una percepción distinta u opuesta respecto de un mismo problema o situación de cambio, que son o aparentan ser contradictorios o excluyentes. Se utiliza la palabra conflicto para referirnos a diversas situaciones que pueden involucrar personas físicas o jurídicas (empresas, estados, corporaciones).

La causa del conflicto reside en que los recursos y las conductas humanas son limitados. La escasez de recursos obliga a elegir, y en la determinación de lo que se elige puede haber divergencia, y por ende conflicto.
Si bien el conflicto puede ser positivo con un correcto manejo, existe la extendida idea de ver al conflicto como algo negativo y, por lo tanto, intentar eludirlo. Por lo general, cuando se presenta un conflicto se lo relaciona con la forma en que se lo suele enfrentar o resolver, ya que no existe una educación adecuada para afrontar la situación de manera positiva.

No obstante, el conflicto es inherente al ser humano como ser sociable que interacciona con otras personas con las que va a discrepar, tener intereses y necesidades contrapuestas. Es ineludible, y por más que se trate de evitarlo, el conflicto continuará su dinámica.

Fecha de recibido: 23/01/2021 - Fecha de aceptación: 24/03/2021 - Publicación en línea: 17/09/2021

Correspondencia: Patrizio Petrone, MD, PhD, FACS; Department of Surgery, NYU Langone Hospital—Long Island, 222 Station Plaza North, Suite 300; Mineola, New York, 11501, USA. Teléfono: +1 (516) 663-9571

Correo electrónico: patrizio.petrone@gmail.com; patrizio.petrone@nyulangone.org

Citar como: Petrone P. Características del conflicto en las organizaciones de salud y estrategias para su resolución. Rev Colomb Cir. 2022;37:21-26. https://doi.org/10.30944/20117582.1478

Este es un artículo de acceso abierto bajo una Licencia Creative Commons - BY-NC-ND https://creativecommons.org/licenses/by-nc-nd/4.0/deed.es 
Visualizar el conflicto como algo positivo permite considerar dos situaciones: por un lado, la diversidad y la diferencia como un valor, ya que al vivir en un mundo plural de cooperación y solidaridad se transforma en fuente de crecimiento y enriquecimiento mutuo, de respeto a la diversidad de opiniones y de percepciones. Por otro lado, solo a través de entrar en conflicto con estructuras complejas o con las personas que las sostienen, la sociedad puede avanzar hacia mejores modelos, en búsqueda de soluciones satisfactorias e innovadoras.

El reto consta en aprender a enfrentar y resolver los conflictos de una manera constructiva y no violenta, a comprender qué es el conflicto y conocer sus componentes, así como desarrollar actitudes y estrategias para resolverlo. Algunos conflictos nacen de la incompatibilidad de caracteres y rara vez pueden terminar en algo beneficioso, mientras que otros conflictos vienen de las diferentes metas y percepciones que tiene cada integrante, tanto para sí como para el equipo, aunque suelen presentarse ambos tipos a la vez.

El conflicto en las organizaciones no es positivo ni negativo en sí mismo, depende de la actitud frente al mismo. Según Goleman, "comprender lo que siente el otro no significa estar de acuerdo con él. Pero anular la empatía para asumir una posición de dureza puede conducir a posturas polarizadas y a callejones sin salida."

\section{Condiciones para la existencia de conflicto}

Primero: que exista una relación de dos o más partes (exceptuando el conflicto intrapersonal).

Segundo: que las partes del conflicto estén interrelacionadas entre sí, de manera que las acciones y las decisiones de cada una afecten al resto. Si no hay interrelación, no habrá conflicto.

Tercero: que las partes del conflicto entiendan que sus objetivos no son totalmente compatibles, si lo fuesen no habría conflicto. Es decir, no pueden existir diferencias sin conflicto.

\section{Fases del conflicto}

\section{Fase 1: Incomodidad y tensión}

En su inicio, un conflicto se desarrolla con lentitud y poca intensidad. Sus señales en la primera fase son difusas y su carácter es más bien personal. Aunque esta fase presenta todavía numerosas opciones para manejar el conflicto de manera constructiva, muchas veces no se actúa a tiempo porque la detección y la interpretación de los primeros indicios son difíciles o difusos, o bien porque no se quiere enfrentar los sentimientos negativos.

\section{Fase 2: Escalada}

La segunda fase se presenta con más celeridad, y la intensidad del conflicto aumenta drásticamente. En esta fase todos los involucrados saben que hay un conflicto y no pueden ignorarlo. Es una etapa crucial donde se decide su solución o el avance directo a su crisis total (Fase 3). Pero si los involucrados logran analizar el conflicto conscientemente con experiencia y disciplina, su resolución constituye todavía una opción viable. Otra posibilidad es la búsqueda de apoyo de alguien neutral para facilitar así el manejo del conflicto. Esa persona podría ser, por ejemplo, el jefe de una organización, quien actúe basado en su posición y autoridad legal. También podría tratarse de alguien a quien se considere neutral y confiable, seleccionado por las partes en conflicto.

\section{Fase 3: Crisis abierta y pública}

En esta fase el conflicto es incontrolable, la crisis es total y los involucrados ya no quieren ni pueden buscar soluciones. Hay una sola opción: ganar o perder. El único apoyo capaz de manejar el conflicto es la intervención de un especialista en mediación.

\section{Abordaje de los conflictos}

Se deben identificar las partes principales de un determinado conflicto y sus características, entre las que encuentran sus orígenes, tipos, creencias y posturas. 


\section{a. Orígenes}

- Conflicto intrapersonal: se presenta en un individuo.

- Conflicto interpersonal: se presenta entre dos o más individuos.

- Conflicto intragrupal: se presenta dentro de un grupo, organización, institución o nación.

- Conflicto intergrupal: se presenta entre dos o más grupos, organizaciones, instituciones o naciones.

De allí la importancia que debe otorgársele a comprender los códigos culturales del otro (lenguaje, arte, tradición y conducta), ya que se trata de un paso esencial, tanto para la prevención como para su resolución.

\section{b. Tipos}

Existen dos clasificaciones aceptadas de los tipos de conflicto, la de Thompson y Hrebec (figura 1) y la de Deutsch.

\begin{tabular}{|c|c|c|c|}
\hline & \multicolumn{2}{|c|}{ REALIDAD } \\
\hline & & Conflicto & No conflicto \\
\hline \multirow{2}{*}{ 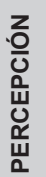 } & Conflicto & Conflicto declarado & Falso conflicto \\
\hline & No conflicto & Conflicto latente & Ausencia de conflicto \\
\hline
\end{tabular}

Figura 1. Matriz de Thompson y Hrebec.

La clasificación de Deutsch consta de los siguientes tipos:

- Verídico: el conflicto existe objetivamente, es improbable que se resuelva con facilidad.

- Contingente: el conflicto depende de circunstancias que se pueden cambiar fácilmente.

- Desplazado: el conflicto expresado es distinto al conflicto central.

- Latente: el conflicto está sumergido, aún no ocurre.
- Falso: el conflicto se basa en una mala interpretación o percepción.

\section{c. Creencias}

Se basa en conocer qué creen las partes que puede ocurrir en relación con los objetivos y los resultados de la resolución. Para ello las alternativas aceptadas se basan en la perspectiva, misma que puede ser competitiva (ganar o perder), o bien, cooperativa (todas las partes ganan o pierden).

\section{d. Posturas}

Los factores que contribuyen a la postura general incluyen:

- Posiciones, que son las actitudes iniciales que adoptan las partes en conflicto.

- Intereses, que representan el contexto en el que puede existir una posición.

- Necesidades, que representan el contexto aún más amplio dentro del que existen los intereses.

\section{Consecuencias negativas del conflicto}

1. El conflicto estimula las emociones en vez de la razón. El flujo de información se reduce a medida que se concentra entre las partes intervinientes. Las decisiones se basan en información incompleta.

2. El conflicto interfiere con el funcionamiento normal de los procesos de la organización. Crea caos, desorden y es ineficiente.

3. La atención se aleja de los objetivos organizacionales a favor de metas personales.

4. Las reacciones humanas típicas frente al conflicto limitan el funcionamiento de la organización (frustración, lucha interna, ausentismo, rotación de personal).

\section{Respuestas frecuentes a los conflictos}

Suele ser imposible elegir si tener o no conflictos, sólo se puede elegir cómo responder ante ellos: 


\section{- Negación}

Una o ambas partes tratan de no ver las señales del conflicto. Temen a la confrontación directa. No reaccionan y esperan que con el transcurso del tiempo desaparezcan los desacuerdos.

- Ventajas: esta estrategia evita reacciones demasiado rápidas y emocionales.

- Desventajas: no se puede manejar el conflicto de manera activa, se niegan las primeras señales, no se trabajan las causas y la dinámica del conflicto sigue desarrollándose.

- Propender a la calma

Ambas partes reconocen las primeras señales, deciden no profundizar ni analizar la situación, y se liberan del conflicto al concentrarse en los objetivos e intereses más importantes y comunes. Las dos partes son capaces de asumir pequeños conflictos como algo normal y cotidiano en la vida profesional.

- Ventajas: esta estrategia funciona en la fase inicial y permite detener la dinámica del conflicto y un análisis más profundo posteriormente.

- Desventajas: el conflicto puede reaparecer en caso de que las causas no sean correctamente analizadas en su momento.

- Buscar compromisos

No se profundiza ni se analiza el conflicto, sino que se busca una solución en la que ambas partes estén de acuerdo.

- Ventajas: es una estrategia pragmática y orientada a resultados, que funcionan solo en la fase inicial del conflicto.

- Desventajas: aquí también el conflicto puede reaparecer en caso de que las causas no sean correctamente analizadas.

- Imposición de poder

Una parte impone una decisión basada en su poder. Esta estrategia es conocida y frecuente dentro de organizaciones jerárquicas.
- Ventajas: es una manera rápida y unilateral de tomar decisiones puntuales.

- Desventajas: la imposición de poder crea automáticamente más conflictos.

- Buscar alianzas

Los involucrados buscan activamente aliados para reforzar su posición. Esta estrategia es frecuente en el ámbito político.

- Ventajas: favorece a una solución temporal del conflicto.

- Desventajas: no se concentra en una solución que beneficie a ambas partes, sino que busca vencer al otro. Con la formación de alianzas, la dinámica del desarrollo del conflicto generalmente toma más fuerza y el mismo se vuelve menos controlable.

\section{Factores que interfieren en la resolución efectiva de conflictos}

- Egos y vanidades de los actores involucrados.

- Dificultades para aceptar la posición o punto de vista del otro.

- Baja o elevada autoestima.

- Pérdida de la perspectiva.

- Rigidez o poca flexibilidad al cambio.

- Dificultades para someterse a una mediación.

- Buscar culpables o asignar culpas.

- Atacar personas y no al problema.

- Sarcasmo.

- Victimización.

- Verbalizar la ira.

- Manejar el conflicto en forma emocional.

- Coerción.

\section{Estilos de resolución de conflictos}

Según el modelo Thomas-Kilmann, se reconocen los siguientes estilos para resolver los conflictos (Figura 2): 
- Competitivo: se origina cuando es necesaria una acción rápida, y uno o varios de los miembros son obligados a cambiar. Suele darse en asuntos impopulares como, por ejemplo, la reducción de presupuestos o medidas disciplinarias. Las necesidades propias son a costa de la otra parte ("gana o pierde").

- Colaborador: cuando se desea encontrar una solución integradora para obtener una mayor implicación ("ganamos todos").

- Evasivo: niega las diferencias. Se presenta cuando no existe posibilidad de satisfacer los intereses propios y la ruptura es más negativa que los beneficios de la resolución ("no pasa nada").

- Complaciente: se presenta cuando la armonía y la estabilidad son imperiosos ("gana el otro").

- Comprometido: es la más sencilla de las estrategias, aunque una o todas las partes queden insatisfechas ("partimos la diferencia").

\section{Modelo escalada / de-escalada del conflicto}

Según van de Vliert, cualquier reacción de las partes, directa o indirecta, a los asuntos conflictivos constituye la gestión del conflicto. Así, se distinguen dos grandes grupos: conductas escalativa y de-escalativa, las que a su vez se caracterizan por ser espontáneas o estratégicas. Se definen las conductas de-escalativas a aquellas que reducen las posibilidades de sentimientos de frustración, disminuyen la ocurrencia de un conflicto a futuro y resuelven o previenen la intensificación del conflicto actual. Las conductas espontáneas son aquellas que no son intencionales, mientras que las estratégicas son las que forman parte de un plan consciente para prevenir o estimular el conflicto.

Dentro de la conducta de-escalativa espontánea se encuentra negar el conflicto, el análisis de la situación y los mecanismos de regulación; mientras que aquellas de-escalativas estratégicas incluyen el cambio de las condiciones

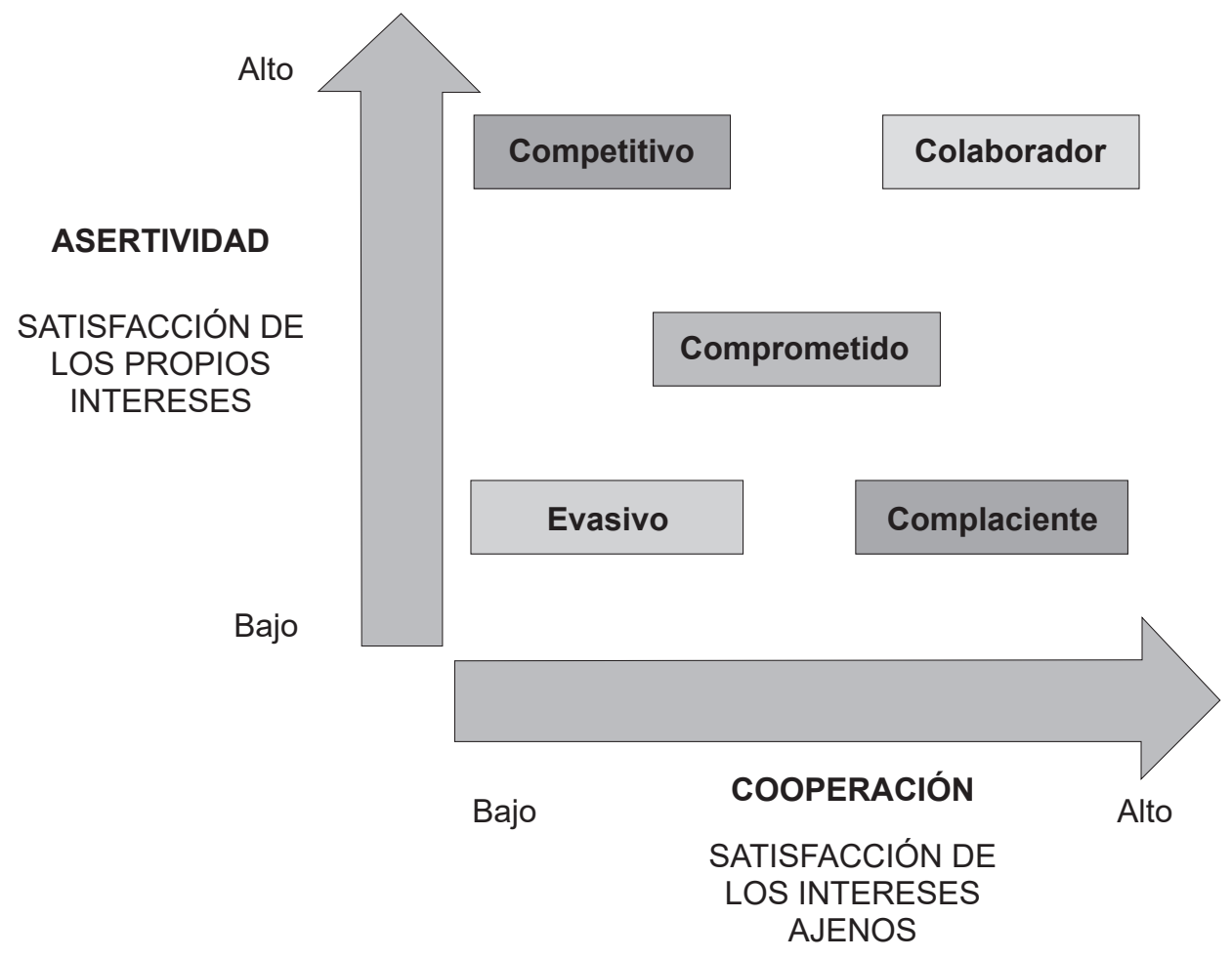

Figura 2. Modelo Thomas-Kilmann de estilos para resolver los conflictos 
antecedentes, la resolución del problema, la reconceptualización de los asuntos conflictivos y la negociación.

Por el otro lado, las conductas escalativas espontáneas son aquellas que tienden a magnificar el problema, y consisten en atacar al oponente, restringir el contacto y establecer actitudes de resistencia como el negativismo, el inconformismo y la construcción de un muro de piedra o stonewalling. Por último, están las conductas escalativas estratégicas como cambiar o ampliar el número de asuntos conflictivos, buscar alianzas y exponer explícita y sistemáticamente los posibles puntos débiles de la otra parte.

\section{Conclusión}

A modo de síntesis, a continuación se presentan las etapas de la resolución del conflicto:

\section{Definir el conflicto}

$\checkmark$ Puntos de controversia.

Intereses de cada parte.

Necesidades de cada uno.

\section{Situar el conflicto}

$\checkmark \quad$ Cada parte valorará qué significa el conflicto para ella.

$\checkmark \quad$ Tratar los puntos concretos del problema sin personalizar.

$\checkmark \quad$ Buscar los elementos en común de las partes.

$\checkmark$ Promover la empatía.

\section{Generar soluciones}

\section{Tomar decisiones}

\section{Verificar la decisión adoptada}

La solución evaluará en qué consiste el problema que se está analizando; cuándo y cómo se detectó la situación actual y, por último, quién es el responsable de la situación y quién el responsable de buscar una solución. $\checkmark \quad$ ¿Es compartida la responsabilidad del buen funcionamiento?

$\checkmark \quad$ ¿Pueden las partes llevar a buen término su compromiso?

$\checkmark \quad$ La solución adoptada, ¿resolverá definitivamente el problema?

De este modo, con base en los procesos de las decisiones tomadas, permitirá continuar o corregir el mecanismo implementado para la resolución del conflicto.

\section{Referencias}

1. Goleman D. Emotional intelligence. New York, NY: Bantam Books; 1995.

2. Goleman D. Working with emotional intelligence. New York, NY: Bantam Books; 1998.

3. Thompson L, Hrebec D. Lose-lose agreements in interdependent decision making. Psychological Bulletin. 1996;120:396-409.

4. Deutsch M. The resolution of conflict. Constructive and destructive processes. New Haven, CT: Yale University Press; 1973.

5. Domínguez Bilbao R, García Dauder S. Introducción a la teoría del conflicto en las organizaciones. Facultad de Ciencias Jurídicas y Sociales, Universidad Rey Juan Carlos. Madrid: Working Papers; 2003.

6. Van de Vliert E, Nauta A, Euwema C, Jansen O. The effectiveness of mixing problem solving and forcing. En: Using conflict in organizations. De Dreu CKW, Van de Vliert R (eds.); pp 38-52. Londres: Sage; 1997.

7. Filley AC. Interpersonal conflict resolution. Glenview, IL: Scott, Foresman; 1975.

8. Gray B. Collaborating: Finding common ground for multiparty problems. San Francisco, CA: Jossey-Bass; 1989.

9. Thomas KW, Kilmann RH. Conflict Mode Instrument. Tuxedo, NY: XICON; 1974.

10. Rubin JZ, Pruitt DG, Kim SH. Social conflict: Escalation, stalemate, and settlement ( $2^{\mathrm{a}}$ ed.). New York: McGrawHill; 1994.

11. Van de Vliert E. Conflict and conflict management. En: Work and Organizational Psychology. Drenth PJD, Thierry H, de Wolf CJ (eds.); $2^{\text {a }}$ ed., pp 351-376. Hove, East Sussex: Psychology Press; 1998.

12. Bisno H. Managing conflict. Newbury Park, CA: Sage; 1988.

13. Goleman D. Conflict management: A primer. Florence, MA: More Than Sound; 2017.

14. Blake W. A poison-tree. En: Songs of Innocence and of Experience; p 70. London: Basil Montagu Pickering; 1868. 